\title{
An Assessment of Changes in the Magnesium Level During Gynecological Abdominal Surgeries
}

\author{
Katayoun Haryalchi, Mandana Mansour Ghanaie, Yasaman Yaghoubi ${ }^{1}$, Forozan Milani, Roya Faraji \\ Reproductive Health Research Center, Alzahra Hospital, School of Medicine, 'Guilan University of Medical Sciences, Guilan, Iran
}

\section{A B S T R A C T}

Background: Magnesium (Mg) is the fourth most common cation in the human body and the second most intracellular cation after potassium. It has a fundamental role in several vital functions. As this essential ion is not measured in routine chemistry panels, little is known about its alterations during intraoperative time. Aim: The present study was designed to determine the negative effects of postoperative hypomagnesemia during and after surgeries. Subject and Methods: This study was a descriptive interventional study involving 74 patients. All patients underwent gynecological abdominal surgeries, and anesthesia protocols were standardized to comprise general and spinal anesthesia. All the patients were aged between 25 and 45 years, with ASA class I and II. Their total serum $\mathrm{Mg}$ level was measured $1 \mathrm{~h}$ before and $2 \mathrm{~h}$ after the surgery. The total serum Mg, calcium, and albumin level were measured by photometric methods. Data were analyzed using SPSS version 16.0 (Chicago Illinois, (USA). Inferential statistic was done using Vilksonnon-parametric and Pearson's correlation test. $P<0.05$ were considered as significant. Results: The mean serum Mg levels were $1.87(0.32) \mathrm{mg} / \mathrm{dl}$ before and 1.55 (0.34) mg/dl after the surgeries (The normal range: $=1.7-2.5 \mathrm{mg} / \mathrm{dl}$ ). Results illustrated a significant hypomagnesemia after operations. Conclusion: Clinical impact of hypomagnesemia during surgeries needs to be studied further. Moreover, surgeons should be warned about the severity of probable electrolyte imbalances induced by perioperative events to decrease associated morbidities.

KEY WORDS: ASA, cation, gynecologic surgeries, magnesium, magnesium level, photometric method, standardized anesthesia, surgeries

\section{INTRODUCTION}

Magnesium $(\mathrm{Mg})$ is the fourth most common cation in the body and the second intracellular cation after potassium. ${ }^{[1-3]}$ It has a fundamental role as a co-factor in more than 300 enzymatic reactions involving energy metabolism and nucleic acid synthesis. ${ }^{[2,4-6]}$ It is also involved in several processes including hormone receptor binding, gating of calcium channels, transmembrane ion influx, and regulation of adenylate cyclase, muscle contraction, neuronal activity, control of vasomotor tone, cardiac excitability, and neurotransmitter release. ${ }^{[2,4,5]}$ In many of its actions, it has been likened to a physiological calcium antagonist. In addition to interaction with calcium, $\mathrm{Mg}$ has a marked effect on the regulation of trans-membrane sodium and potassium movement. ${ }^{[3,5-8]}$ Intracellular Mg ion concentration

\begin{tabular}{|l|l|}
\hline \multicolumn{2}{|c|}{ Access this article online } \\
\hline Quick Response Code & Website: \\
\hline 回 & www.jbcrs.org \\
\cline { 2 - 2 } & \\
\hline
\end{tabular}

blocks outward sodium and potassium currents, whereas extracellular $\mathrm{Mg}$ ion concentration generally has an activator effect on ionic transport. Both $\mathrm{Mg}$ ion concentrations stimulate sodium-potassium ATPase at low concentrations and causes inhibition at high concentrations. ${ }^{[3,5,9]}$ This indicates that $\mathrm{Mg}$ has an important role in the movement and muscle activity after major abdominal surgeries..$^{[10]}$ It is therefore important to prevent deep vein thrombosis (DVT), improve well-being or earlier discharge, and have less duration of hospitalization and costs.

Considering the significant role of $\mathrm{Mg}$ on biochemical properties and because serum $\mathrm{Mg}$ levels are rarely measured in routine chemistry panels, little is known about the perioperative alteration of this electrolyte and the extent and impact of postoperative serum $\mathrm{Mg}$ changes in general surgery patients. Case series of postoperative measurements after general anesthesia and general surgeries remain few and unclear.

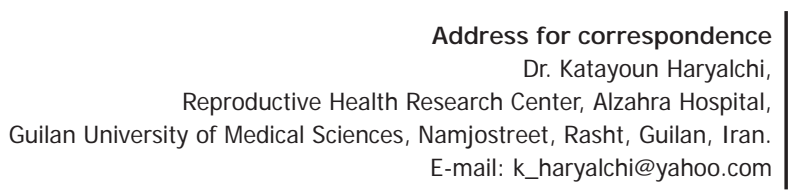


Hypomagnesemia and its impact on postoperative morbidity and mortality should be focused on. For instance, hypomagnesemia can lead to atrial dysrhythmias, lower cardiac output, and death after $\mathrm{CABG}$; other reports have also suggested a possible link between a decrease in total serum $\mathrm{Mg}$ and an increase in the risk of postoperative mortality. ${ }^{[10-12]}$ Hypomagnesemia has a negative effect on critically ill patients as well. ${ }^{[10]}$ Therefore, the present study was designed to review the extent of changes in the levels of serum $\mathrm{Mg}$ after gynecological abdominal surgeries to identify causative or associated factors and to correlate these changes with postoperative outcomes like cardiac dysrhythmias, cardiac output, muscle contraction, neuronal activity, control on vasomotor tone, cardiac excitability, and neurotransmitter release..$^{[5,6,13,14]}$

\section{SUBJECT AND METHODS}

The study took place at a maternity centre (Alzahra Hospital). The plan of the study was approved by a local ethics committee at Guilan University, and informed consents were obtained from all patients. We included 74 patients in our study who underwent gynecological abdominal surgeries and had American Society of Anesthesiologists (ASA) physical status I and II. Sampling was convenient and the study was descriptive interventional. Patients with prior abdominal surgeries, major systemic illnesses, having received calcium-channel blockers, with renal dysfunction, and with a history of neuropathy, myopathy, pulmonary hyperventilation, hypothermia, alkalosis, and hypomagnesemia or massive blood transfusion during surgery were excluded from the study. Anesthesia protocols were standardized. Patients were fasted orally for $6 \mathrm{~h}$ before surgery. General anesthesia was induced with thiopental sodium $(5-7 \mathrm{mg} / \mathrm{kg})$ and tracheal intubation was facilitated with $1 \mathrm{mg} / \mathrm{kg}$ succinylcholine. Anesthesia was maintained with $50 \%$ nitrous oxide in oxygen, atracurium, and $0.5-1 \%$ isoflurane. Fentanyl $(0.1 \mathrm{mg} / \mathrm{kg})$ was administered intravenously (IV) at induction of anesthesia, and subsequent incremental doses were given if a patient had sweating, lacrimation, or a $20 \%$ increase above baseline in heart rate (HR) or blood pressure. The total amount of atracurium and fentanyl administered were recorded constantly. HR, pulse oximetry, and noninvasive blood pressure (NIBP) were monitored precisely. At the end of surgery, neuromuscular blockade was reversed with $0.05 \mathrm{mg} / \mathrm{kg}$ neostigmine and $0.02 \mathrm{mg} / \mathrm{kg}$ atropine. The regional anesthesia protocol consisted of inter-spinal administration of xylocaine and epinephrine. If necessary, narcotics or anxiolytics were used parenterally. Throughout anesthesia, administration of crystalloids, synthetic colloids, or blood products were performed entirely at the direction of the individual anesthesia providers and were not influenced by our protocol (no massive blood or fluid replacement). Clinical data such as age, gender, and weight of the patient, as well as the duration of the surgery, urine output, blood loss, and IV fluids were recorded for each patient individually.

All patients were aged between 25 and 45 years and were candidate for major or minor gynecological abdominal surgeries (TL, myomectomy, ovarian cyst, cesarean, and hysterectomy). Samples collection was done according to a convenient sampling. All questionnaires were filled in to demonstrate demographic information, physical situation, or vital signs.

Blood samples were obtained (2cc) on the day of surgery $1 \mathrm{~h}$ before and the second sample was obtained $2 \mathrm{~h}$ after the surgery. All samples were sent to the same laboratory for electrolyte assessment (Ca, Mg, albumin). Total serum calcium, Mg, and albumin level were measured by phothometric method. Data were analyzed with Vilkalsonnon-parametric and Pierson correlation test for comparison between main variables and quantitative parameters changes between $1 \mathrm{~h}$ before and $2 \mathrm{~h}$ after surgeries. Data were analyzed using SPSS version 16.0 (Chicago Illinois, USA). Inferential statistic was done using Vilksonnon-parametric and Pearson's correlation test. $P<0.05$ were considered as significant.

\section{RESULTS}

We identified 74 patients who referred to our centre for gynecological abdominal surgeries. The mean (SD) for age was 26.1 (6.1 year) between cases. The youngest patient was 18 and the oldest was 45 years old; approximately $75 \%$ (55/74) of the patients were younger than 30 years; $98.6 \%$ of them were married and $1.4 \%$ unmarried. The percentage of previous surgery, spinal anesthesia, and the history of previous anesthesia past medical disorders were respectively $12.16 \%, 93.2 \%, 10.8 \%$, and $13.5 \%$. According to the type of surgery, cesarean, hysterectomy, and laparatomy, the statistics showed respectively $80.1 \%$, 9.45\%, and $9.4 \%$ [Table 1 ].

First, one sample for Kolmogorov-Simivnor test was applied to assess normal distribution of variables like albumin, calcium, $\mathrm{Mg}$, and vital signs. However, then it was apprehended as the results did not follow a normal distribution. It was then replaced with Vilksonnonparametric test to get more precise results to compare between average of variables (before and after surgeries).

Relation between demographic quantitative parameters (age, weight, previous surgery, and type of anesthesia) and basic variants (albumin, calcium, Mg, blood pressure, pulse, 
respiratory rate, and temperature) was assessed by Pearson correlation coefficient test. There was a direct significant correlation in total serum $\mathrm{Mg}$ before and after all type of surgeries $(P<0.001, \mathrm{R}=0.562)$ [Table 2].

The Table 3 presented a significant correlation between main variables before and after surgeries. However, there was an exception for temperature $(P=0.07)$. Furthermore, there were no significant correlation between variants before and after surgeries for the purpose of previous anesthesia, surgery, and disorders. According to the type of anesthesia, there was a significant correlation between before and after surgeries in the purpose of changes in blood pressure $(P=0.03)$ and Table 2 .

The mean serum $\mathrm{Mg}$ levels were 1.87) 0.32 (before and 1.55) 0.34 (after surgeries (Normal total serum $\mathrm{Mg}=1.7-2.5 \mathrm{Mmol} / \mathrm{l}) .^{[14,15]}$ Therefore, as illustrated in Table 3, there was a meaningful hypomagnesemia after these types of surgeries. Albumin changes before and after surgeries had a significant relevance with blood pressure

\begin{tabular}{lcc}
\hline \multicolumn{2}{c}{ Table 1: Demographic data of subjects } \\
\hline Relative frequency & Number & Percentage \\
\hline Age & 15 & \\
$<25$ years & 42 & 20.3 \\
$25-30$ years & 17 & 56.8 \\
$\quad>30$ years & & 22.9 \\
Marriage condition & 73 & \\
$\quad$ Married & 1 & 98.6 \\
Single & 9 & 1.4 \\
Previous surgery & 69 & 12.2 \\
Spinal anesthesia & 10 & 93.2 \\
Past medical disorder & 8 & 13.6 \\
History of previous anesthesia & & 10.8 \\
\hline
\end{tabular}

Table 3: Comparison between main variables before and after surgeries

\begin{tabular}{|c|c|c|c|c|c|}
\hline \multirow[t]{2}{*}{ Main variable } & \multicolumn{2}{|c|}{ Before surgery } & \multicolumn{2}{|c|}{ After surgery } & \multirow[t]{2}{*}{$P$ value } \\
\hline & Mean & SD & Mean & SD & \\
\hline Albumin (mmol/l) & 4.002 & 0.461 & 4.007 & 1.07 & $<0.001$ \\
\hline Calcium (mmol/l) & 8.75 & 0.323 & 8.4 & 0.46 & $<0.001$ \\
\hline Magnesium (mmol/l) & 1.87 & 0.32 & 1.55 & 0.34 & $<0.001$ \\
\hline Blood pressure $\mathrm{mmHg}$ & 11.7 & 1.34 & 96.37 & 1.8 & 0.03 \\
\hline Pulse/min & 83.28 & 8.23 & 87.04 & 9.53 & $<0.001$ \\
\hline Respiration/min & 18.74 & 4.93 & 21.33 & 2.1 & 0.10 \\
\hline Temperature-c & 37.38 & 0.87 & 37.14 & 0.93 & 0.07 \\
\hline
\end{tabular}

Table 2: Balance of electrolytes, albumin, and changes in vital signs according to the type of anesthesia

\begin{tabular}{|c|c|c|c|c|c|}
\hline \multirow{2}{*}{$\begin{array}{l}\text { The type of anesthesia } \\
\text { Balance of electrolytes and } \\
\text { albumin-changes in vital signs }\end{array}$} & \multicolumn{2}{|c|}{$\begin{array}{c}\text { General } \\
\text { anesthesia }\end{array}$} & \multicolumn{2}{|c|}{$\begin{array}{c}\text { Spinal } \\
\text { anesthesia }\end{array}$} & \multirow[t]{2}{*}{$P$ value } \\
\hline & Mean & SD & Mean & SD & \\
\hline Diff-albumin & 0.46 & 0.89 & 0.53 & 11.2 & 0.84 \\
\hline Diff-Calcium & 0.4 & 0.89 & 0.34 & 0.53 & 0.82 \\
\hline Diff-Magnesium & 0.32 & 0.81 & 0.31 & 0.38 & 0.98 \\
\hline Diff-blood pressure & 42 & 34.1 & 20.94 & 20.11 & 0.03 \\
\hline Diff-pulse & 1.2 & 10.7 & 3.9 & 7.9 & 0.47 \\
\hline Diff-respiration & 7 & 6.6 & 3.28 & 22.4 & 0.31 \\
\hline Diff-temperature & 0.08 & 0.69 & 0.26 & 1.2 & 0.55 \\
\hline
\end{tabular}

changes $(P=0.03)$. There was no significant relevance in other parameters. Furthermore, there was no significant relevance between variants before and after surgeries for the purpose of previous anesthesia, surgery, or disorders. But, there were significant relevance for blood pressure changes before and after surgeries in cesarean, laparatomy, and hystrectomy $(P=0.08)$. According to the type of anesthesia, there was a meaningful relationship between before and after surgeries for the purpose of blood pressure changes $(P=0.03)$.

Finally, as presented in Table 3, the calcium level decreased significantly after surgeries, but there was no hypocalcemia. There was a decrease in total serum calcium level, unlike that for $\mathrm{Mg}$. Because, according to the results shown in Table 3, the mean total serum Mg level became $<1.7 \mathrm{mg} / \mathrm{dl}$ (1.55(0.34)), indicating significant hypomagnesemia.

\section{DISCUSSION}

In the present study, we assessed changes in total serum $\mathrm{Mg}$ level during gynecological abdominal surgeries. There are significant alterations in laboratory parameters during abdominal surgeries. Many of those are well known and measured routinely.$^{[3,12-19]}$ For example, postoperative serum potassium or hematocrit levels were assessed routinely for replacement or transfusion. Other parameters like serum albumin or total calcium level reflect the magnitude of fluid and electrolyte imbalances caused by the operative procedures and its anesthesiologic resuscitation. ${ }^{[2,12,19]}$ However, in case of serum $\mathrm{Mg}$, these problems are less clear. Studies have not examined the magnitude of alteration in postoperative $\mathrm{Mg}$ level in gynecological abdominal surgeries or its impact on postoperative outcome in females only..$^{[3,12-18,20 \mid}$ Postoperative hypomagnesemia has been reported in other types of operation like major cancer series, cardiac, colorectal surgeries, thyroidectomies, and spinal fusion. ${ }^{[13-18,20,21]}$

Recompense of lowered serum Mg perioperatively has some benefits. For example, reduction in cardiac dysrhythmias, primary atrial tachyarrhythmias, ${ }^{\mid 11,13-15,22]}$ reduced anesthetic need when given as an adjunct to general anesthesia, inhibition of platelet dependent thrombosis, attenuate adverse cardiovascular effects during laryngoscopy, and intubation. ${ }^{[14,15]} \mathrm{Mg}$ also has therapeutic indications in postoperative recovery care. ${ }^{[3-5,10,23]}$ In comparison to calcium, total serum $\mathrm{Mg}$ poorly correlate with intracellular $\mathrm{Mg}$ concentration (in myocardium or skeletal muscle). ${ }^{[11,19,23,24]}$ Ionized $\mathrm{Mg}$ level makes more physiological changes that are relevant to morbidity. ${ }^{[12,24,25]}$ We could not measure ionized $\mathrm{Mg}$ for some laboratory restrictions, therefore there is no comment on that parameter. 
What can explain the mechanisms that lead to lower $\mathrm{Mg}$ level perioperatively? It probably depends on serum loss and IV fluid replacement, perioperative bowel preparation with sodium phosphate purgatives, ${ }^{[2,13-15]}$ citrate administration, and prior therapy with beta-blockers that have been presented by other authors. ${ }^{|7,13-18|}$ However, these factors did not seem to play an important role in our patients, because we excluded all those risk factors before the study. Other causes of hypomagnesemia related to total albumin and protein reduction. It has been shown that these amounts decrease during surgeries before studies. ${ }^{[12,14,15,19]}$ The total protein and albumin concentrations decreased in correlation with fluid administration. ${ }^{[11,19]}$ Indeed, our study illustrated their changes clearly. It is notable that the major reason of the intraoperative decrease for serum $\mathrm{Mg}$ level included fluid dilution with crystalloids or massive blood transfusion. ${ }^{[14,15]}$ But, we had a restriction for fluid replacement even after major hysterectomy up to 31 and, on the other hand, massive blood transfusion was excluded from the study. Another cause of hypomagnesemia related to acid-base statement and alteration in circulating protein level (specially albumin). ${ }^{[14,23,24,26]}$ Therefore, alkalosis could be a major cause of $\mathrm{Mg}$ depletion. ${ }^{[11,19,24,26]}$ We excluded all conditions that lead to alkalosis, but albumin loss was inevitable during the study.

In this respect, albumin changes, calcium alterations, loss of renal function, or malnutrition could play an obvious role on $\mathrm{Mg}$ level in our study. We noticed a depletion in albumin and calcium levels; thus, urine loss or malnutrition could not be improbable also. ${ }^{[11,13-15]}$ Moreover, for low socioeconomic class, malnutrition or less $\mathrm{Mg}$ and calcium levels cannot be ignored.

\section{CONCLUSION}

Our study illustrates the variation of serum $\mathrm{Mg}$ concentration during major gynecological abdominal surgeries meaningful decrease in $\mathrm{Mg}$ level. The fluctuation depends on serum albumin, calcium, urine loss, or malnutrition. ${ }^{[1,15,19,26]}$ Our study suggest that surgeons should be aware of the severity of electrolyte imbalance induced by perioperative events that accompany gynecological abdominal surgeries. They may also consider monitoring or correcting changes routinely to prevention morbidities in high-risk patients. Finally, we could say that the impact of postoperative hypomagnesemia and its impression on postoperative outcome ${ }^{|13-18|}$ such a slow cardiac response, less pain control, inadequate muscle tone, and shortage in well-being need larger-scale trails. May be with timely diagnosis, we can prevent bad outcomes or morbidities in our centre and bring more satisfaction for patients, less hospitalization, and costs.

\section{REFERENCES}

1. Rouilly M, Russterholz B, Spichiger U, Simon W. Neutraliophorebased selective electrode for assaying the activity of magnesium in undiluted blood serum. Clin Chem 1990;36:466-9.

2. Preston R. A management current in paramecium. Science 1999;250:285-8.

3. Fawcett WJ, Haxby EJ, Male DA. Magnesium: Physiology and pharmacology. Br J Anesth 1999;83:302-20.

4. Zologa G, Wilkens R, Tourville J. A simple method for determining patients. Crit Care Med 1987;15:813-6.

5. Massry S. Pharmacology of magnesium. Ann Rev Phamacol Toxicol 1977;17:67-82.

6. Whang R. Magnesium deficiency, pathogenesis, prevalence and clinical implications. Am J Med 1987;82:24-9.

7. Barbour RL, Altura BT, Gupta RK. Influence of magnesium on cardiac performance, intracellular $\mathrm{Mg}$ and $\mathrm{pH}$ as assessed with P-NM spectroscopy. Proc Am Soc Magnesium Res, La Jolla, CA, 1991.

8. Zaloga G. Interpretation of the serum magnesium level. Chest 1989;95:257-8.

9. Tzivoni D, Keren A. Suppression of ventricular arrhythmia by magnesium. Am J Cardiol 1990;65:1397-9.

10. Hebert P. Functional magnesium deficiency in critically ill patients identified using a magnesium loading test. Crit Care Med 1997;25: 749-54.

11. Bianchi P, Lui D. Calcium dependent magnesium uptake in myocardium. Life Sci 1993;52:1225-9.

12. Lanzinger MJ, Moretti EW, Wilderman RF, El-Moalem HE, Toffaletti JG, Moon RE. The relationship between ionized and total serum magnesium concentrations during abdominal surgery. J Clin Anesth 2003;15:245-9.

13. Raj KS, Keane-Miller C, Golden NH. Hypomagnesemia in adolescents with eating disorders hospitalized for medical instability. Nutr Clin Pract 2012;27:689-94.

14. Schwarz RE, Nevarez KZ. Hypomagnesemia after major abdominal operations in cancer paitients: Clinical implications. Arch Med Res 2005;36:36-41.

15. Ntonas G, Njau SN. Perioperative changes in serum magnesium concentration during cholecystectomy with general anaesthesia. Aristotle Univ Med J 2007;34:49-53.

16. Chrun LR, Joao PR. Hypomagnesemia after spinal fusio. J Pediatr (Rio J) 2012;88:227-32.

17. Verhelst L, De Schepper J, Sergeant G, Liekens K, Delport H. Variation in serum electrolyte concentrations and renal function after therapeutic hip arthroscopy: A pilot study. Arthroscopy 2009;25:377-81.

18. Evans MD, Barton K. Plasma magnesium should be monitored perioperatively in patients undergoing colorectal resection. Colorectal Dis 2009;11:613-8.

19. Lepage R, Legare G, Racicot C. Hypocalcemia induced during major and minor abdominal surgery in humans. J Clin Endocrinol Metab 1999;84:2654-8.

20. Place HM, Enzenauer RJ, Muff BJ, Ziporin PJ, Brown CW. Hypomagnesemia in postoperative spine fusion patients. Spine 1996;21:2268-72.

21. Sanchez-Capuchino A, McConachie I. Peri-operative effect of major gastrointestinal surgery on serum magnesium. Anesthesia 1994;49:912-4.

22. Kost G. New whole blood analyzers and their impact on cardiac and critical care. Crit Rev Clin Lab Sci 1993;30:153-202.

23. Sircus M, Linda OM. Safer surgery with magnesium before, during, and after F.I.G.H.T for your health 1120,2009.

24. Fleisher M, Norman D, Gladstone M, Evaluation of ionized magnesium and calcium in cancer patients. Clin Chem 1993;39:1178.

25. Barrera R, Fleischer M, Miletic J, Groeger J. Ionized magnesium supplementation in critically Ill patients: Comparing ionized and total 
magnesium. J Crit Care 2000;15:36-40.

26. Landerson JH, Lewis JW, Boyd JC. Failure of total calcium corrected for protein, albumin and $\mathrm{pH}$ to correctly assess for calcium status. J Clin Endocrinol Metab 1978;46:986.
How to cite this article: Haryalchi K, Ghanaie MM, Yaghoubi Y, Milani F, Faraji R. An assessment of changes in the magnesium level during gynecological abdominal surgeries. J Basic Clin Reprod Sci 2013;2:110-4.

Source of Support: Nil, Conflict of Interest: None declared

\section{New features on the journal's website}

\section{Optimized content for mobile and hand-held devices}

HTML pages have been optimized of mobile and other hand-held devices (such as iPad, Kindle, iPod) for faster browsing speed.

Click on [Mobile Full text] from Table of Contents page.

This is simple HTML version for faster download on mobiles (if viewed on desktop, it will be automatically redirected to full HTML version)

\section{E-Pub for hand-held devices}

EPUB is an open e-book standard recommended by The International Digital Publishing Forum which is designed for reflowable content i.e. the text display can be optimized for a particular display device.

Click on [EPub] from Table of Contents page.

There are various e-Pub readers such as for Windows: Digital Editions, OS X: Calibre/Bookworm, iPhone/iPod Touch/iPad: Stanza, and Linux: Calibre/Bookworm.

\section{E-Book for desktop}

One can also see the entire issue as printed here in a 'flip book' version on desktops.

Links are available from Current Issue as well as Archives pages.

Click on View as eBook 